\title{
Hybrid Content Analysis of the Most Popular Politicians' Selfies on Twitter
}

\author{
MANOLO FARCI, Department of Communication Studies, University of Urbino \\ MARIO OREFICE, Department of Communication Studies, University of Urbino
}

\begin{abstract}
The growing presence of selfies on the Web proves how personal photography is changing its role: from a tool for documenting everyday lives to an identity-building resource used to create life narratives, to be shared with a public that is constantly connected online. Our definition of a 'selfie' includes those personal snapshots that: (a) are created with the awareness of belonging to a specific genre of self-portraits; (b) combine textual and iconic dimensions; and (c) are distributed in one's own social network. Our claim is that selfies offer the opportunity to experiment with diverse prospects of self-presentation, especially thanks to their framing power. Using Goffman's theory, we claim that every selfie produces a framing effect that can relate more or less with the main frame in which the snapshot is taken. The aim of this paper is to explore how the framing effect of a selfie affects the politics of self-representation of individuals whose role expectations are quite obvious, such as political figures. Taking advantage of this framing effect, our findings show how politicians use selfies as a strategic self-promotion tool.
\end{abstract}

\section{KEYWORDS}

selfie, twitter political branding, visual content analysis, framing effect 


\section{Introduction}

Nowadays, numerous practices related to the transmission, encoding, ordering or reception of images are emerging thanks to the increased integration of cameras inside mobile devices, such as tablets \& smartphones (Hand 2012). The latest hype is surely the selfie. According to Twitter's 2014 top trends, the generic term 'selfie' was mentioned more than 92 million times 12 times more than the previous year ${ }^{1}$. Nevertheless, this selfie-mania is much more than just another cleverly named craze or the latest web photo trend ${ }^{2}$. The increasing presence of selfies is raising many theoretical issues, ranging from the use of self-portraits as an identity-building tool (Dobson 2014; Seko 2013; Piela 2013) to the relationship with notions of personal media (Lüders et al. 2010), public sphere (Iqani 2013), social capital (Schwarz 2010), or the rules of composition governing the process of selfie-taking by individuals who had never received formal training in photography before (Bruno et al. 2013).

Within the realm of this paper, our definition of a 'selfie' is any personal snapshot that: (a) is created with the awareness of belonging to a specific genre of self-portraits; (b) combines iconic and textual dimensions; and (c) is distributed within one's social network on sites such as Facebook, Twitter or Instagram. Starting from this definition, we claim that every selfie practice develops a framing effect that can relate more or less with the main frame in which the snapshot is taken. This paper aims to understand how the framing effect of a selfie affects the politics of self-representation (Burgess, Vivienne 2013), especially of those people whose role expectations are clearly of public domain, as in the case of political figures. If role expectations are viewed as actions or qualities expected from the occupant of specific frames, taking a selfie should represent a way to reinforce, enlarge or break with the frame of traditional political activity. Thus, this research hypothesis can be broken down into two distinct research queries:

(a) How are specific styles of expression, aesthetic elements or technical skills of a selfie used by politicians to update their own traditional image? (b) To what extent does the framing effect of a selfie contribute to redefine the strategies of political identity management?

As you will see through the next sections, our findings shed light on how politicians adopt the framing effect of selfies as a strategic tool for self-promotion.

1 http://www.bbc.com/news/blogs-trending-30394875

2 http://www.theweek.co.uk/people/59769/usies-vs-selfies-the-latest-web-photo-trend 


\section{The framing effect of a selfie}

The act of taking a self-portrait with a mobile device involves, at least, three specific issues: cultural, aesthetic and technological. Which leads to the concept that a selfie has three dimensions, as a cultural object, a form of representation and a user-generated content (UGC) shared within online social networking sites. First of all, the selfie is a form of reflection in which you distinguish yourself from other people and look for recognition, seeking something unique about yourself. So, the selfie is probably the latest way of crafting the self through the use of digital technology. Actually they are part of a long tradition that belongs to the history of visual self-portraits as well as of written autobiographies, memoirs or diaries: the use of technology as a tool for in-depth understanding, visualization or self-improvement (Walker Rettberg 2014). The capability of acquiring self-consciousness when we look at ourselves belongs to the history of human beings: through an image, our external face meets with our internal consciousness and we have the chance to assess ourselves or think about ourselves (Fausing 2013). For this reason, in the execution of a selfie, the camera acts as a mirror reflecting two elements of our body: the face and the gaze. Whereas the face shows the self's bodily appearance, providing space and personality to many anonymous individuals, the gaze is our most intense and intimate form of communication (Berger 1972; Mulvey 1975; Sturken \& Cartwright 2009). This explains why our cultural and moral norms tell us that it is not nice to stare or gape at someone, except in special moments of confidence. Focusing on the face so closely and for such a long time, means that the selfie causes a disruption of the boundaries that mark the person's private space. If distance is culturally conditioned, the selfie invades the invisible bubble reserved for whispering and embracing those people with whom we share greater intimacy (Hall 1963).

Secondly, the selfie is part of the broader social process of home mode communication (Chalfen 1987). As such, it draws on the same logic of satisfactory evidence derived from popular images such as snapshots and related forms of home media. In home mode communication, the reflective stance that ordinary people take in front of their personal photographs is more focused on the product than on the process. For this reason, in contrast with traditional patterns of formal studio shots, snapshots are often characterized by 'disruptions' of formal photographic traditions - off lighting, poor focus, blurred images, awkward poses, harsh shadows (Schroeder 2012). This informality displays how the photographer does not have full control over it. The camera is not invasive: with point-and-shoot cameras, what becomes interesting is the photographer seen as auteur rather than a mere technician. The lack of image quality is perceived as creative incentive rather than a tech-rooted limitation. The same thing denotes a selfie: by displaying the act of taking a photo, through the presence of the outstretched arm or the smartphone in the picture, the selfie does not erase the trace of human production. Rather, it appears as an act of deliberative 
improvisation that is less formal and more authentic. A selfie becomes an important style in strategic communication for projecting an appearance of spontaneity, both for ordinary people as well as the advertising segment. Moreover, the wide usage of photo-software for mobile devices such as Instagram, Instaplus, Picfx or Retrica, enabling the user to further simulate the visual language of analogue photography, creates an aesthetic of digital imprecision and nostalgia. These visual signs of memory, age and time, as well as human and technological errors, achieved through a series of filters, generate a simulacrum of analogue authenticity (Chandler and Livingston 2010).

Finally, creating and sharing a selfie is not simply an act of presentation through a self-portrait snapshot. A selfie is a digitally mediated representation that puts together textual - hashtags, captions and comments - and an iconic dimension, produced with the awareness of belonging to a specific genre and spread across an individual's social network on social networking sites such as Facebook, Twitter or Instagram. The selfie is probably the most ritualized and conventionalized practice of self-representation currently existing on the Web. Repetition seems endemic to this genre: despite the fact that each selfie captures a unique pose, this same pose obediently repeats millions of other very similar stances. Every selfie is nothing more than a visual cliché, an infinite reproduction of the same thing (Berger 2011). This methodic peculiarity of the selfie contributes to its spreadable nature (Jenkins 2013). Once the snap is taken, downloaded and shared through the Web, it is impossible to control what is going to be done with it and who is going to have access to it. Marked with a hashtag, a selfie becomes part of a mediated architecture that filters, orders and redistributes our performances for mutual and often asynchronous benefits (Hogan 2010). Sharing a selfie may lead to the development of an imagined audience related to the use of personal self-portraits (Marwick and boyd 2010), supporting a complex game of gazes, where people are both, the subject taking the picture as well as the object pictured. In this way, they can see themselves through someone else's eyes, or through the impartial eye of a machine, as a text to be analyzed and criticized from a third party, just like any other mediated text. This awareness of being public in public (Boccia Artieri 2012) produces a kind of embodied vision that allows people to perform and to see their own identity and body in different ways (Lasén and Gómez-Cruz 2010).

Starting from these reflections, we derive that one of the main issues related to the current success of selfies is their framing effect. According to Erving Goffman, all our social experiences are organized and structured in terms of framework: a framework is an operating fiction that helps our individual perception in deciding 'what it is that is going on' and determining 'what is relevant' in a given event or experience. A correspondence is thus claimed between perception and the organization of what is perceived. 
When the individual recognizes a particular event, he tends to imply in this response one or more framework or schemata of interpretation of a kind that can be called primary. Primary frameworks vary in degrees of organization. Some are neatly presentable as a system of entities, postulates, and rules: others - indeed, most of the others - appear to have no apparent articulated shape, providing only a lore of understanding, an approach or a perspective. The degree of organization can be of any sort, however each primary framework allows its user to locate, perceive, identify, and label a seemingly infinite number of concrete occurrences defined in its terms $(1974,21)$.

In our society all events - without exception - can be contained and managed within the conventional social meanings. These social meanings affect more than just the participants in an activity: bystanders who merely look are deeply involved as well. But, as Goffman stated, the meaning of a primary framework can be transformed in several ways. Keying is the process of transformation of an activity that is already meaningful as a primary framework into something patterned on it but seen by the participants to be something quite different, such as ceremonies, fantasies, plays, ceremonies. Each transformation adds a layer or lamination to the primary framework. Fabrication is another process for transforming frames of meaning: it is the process whereby another actor is induced into a false belief about what is going on: self-deception is a possible form of fabrication, whereas, at the same time, it might be said that theatre is some sort of voluntarily assisted benign fabrication.

Framing is not a perfect process, people mis-frame, frame unclearly or frame argumentatively. Arguably, frames organize involvement as well as meaning. Given that the frame applied to an activity is expected to enable us to come to terms with all events in that activity, it is understandable that an appropriate behavior might occur, placing the principles of organization in doubt and reopening the question of 'what is going on here?' In this case, a break may happen in the applicability of the frame, a break in its governance.

When people snap a selfie, the framework of this act is given by two factors. The first one is linked to the context where the picture is taken. In the tradition of home mode photography (Chalfen 1976), the 'frames' defined by context and social events have always had a central role in justifying and signifying the act of taking a picture: rarely the photographs were taken in private places such as bedrooms, bathrooms or other rooms in which everyday life takes place. In the same way, it was not common to see pictures 'of the outside' which are not settled in some particular place, like for example touristic, historical or artistic sites. Although everyday activities have never been considered as traditional photographic subjects, there were socially important events - such as baptisms, weddings, birthdays, and other transitional moments - 
during which to not take a photograph seemed inappropriate. With the selfie, every context or social event can represent a good background for a photography, worthy to be celebrated and remembered (Murray 2008).

The second factor is connected to the textual dimension - tags, captions and comments - that accompanies images and contributes to redefine their meaning, making them available to a large and potentially unknown public. A selfie can be produced and submitted with a specific audience in mind, but those who view and react to this content may be different from those for whom it was intended (Hogan 2010): the affordances that shape many of the mediated environments created by social media are often designed to eliminate contextual cues, increasing the likelihood that a user-generated content will be found out of context (boyd 2014).

All this proves how a selfie is not just an unscheduled bracket within an activity, but it can add other lamination that modify the frame in which the photographical action is taking place, complicating above all the person-role formula. As suggested by Goffman, whenever an individual acts in an episode of an activity, a distinction will be drawn between what is called the person and the particular role he plays during that act. The nature of a particular frame will be linked to the nature of a persona-role formula it sustains (1974). When someone's role expectations are particularly apparent, as in the case of a political figure, taking a selfie means that he is displaying an out-of-frame behavior. With this out-of frame behavior, he is reaffirming the right to sustain or fall back upon a self that is separate from the one relevantly projected. In this way, role gives way to person. We sustain that, showing the person beyond the role, politician's selfies provide a way to reinforce, enlarge or break the frame of political activity as well as strengthen the traditional mechanism of political celebration (Marsh et al. 2010).

Nowadays, political party systems, especially within many Western post-industrial democracies, are facing an increasing pauperization of content such as policies or long-term development programs, losing consensus among militants and supporters (Dalton, Wattenberg 2000; Benoit, Laver 2006). Therefore, this loss has been replaced by a leaderization of politics (McAllister 2007; Adam and Maier 2010) relying on the body and private life of charismatic leaders rather than in traditional organizations such as political parties (Campus 2002; Helms 2005). Thanks to the growing number of communication opportunities provided by media technologies, we are witnessing a radicalization in the concentration of power on individual actors. Political figures, in fact, are increasingly becoming the result of celebrification (West and Orman 2003; Dakhlia 2010) or entertainmentization (Karvonen 2009). These processes are based on the following characteristics: a) focus on leaders treated as show celebrities permanently looking for public success or consensus through the media realm (Stanyer 2008; Campus 2010); b) introduction of a temporal dimension characterized by a sort of permanent political campaigning (Larsson 2014) in which politicians use the media (old as well as new) in order to fight each other for obtaining 
votes in the same way in which it happens for TV talk shows or talent shows (Baum 2005; Stanyer 2013); c) growing convergence between popular culture and the political system (van Zoonen 2005) and, consequently, a paradigmatic shift from deliberative democracy rooted in civil society to audience democracy (Manin 2010) based on the conversion of politicians and political issues in media narratives.

From our point of view, the growing use of selfies by political leaders as well as their wide dissemination through social media like Facebook or Twitter proves how the practice of selfportraits facilitates new forms of performative politics. A performative politics foregrounds the politician as an actor, whose performance on the public stage is continuously judged in terms of authenticity, honesty and 'character' (Corner and Pels 2003).

\section{Method}

In order to understand how politicians' selfies affect the frame of political activity and exploit the mechanism of political mediatization, we analyzed the official Twitter profiles of the ten most popular global politicians, with the highest amount of followers. Using the free software Topsy $^{3}$, we looked at one year of Twitter activity ranging from December, 1st 2013 to December 1st 2014 and selected all those images that were compliant with our definition of a selfie. Through this sampling technique, we obtained a significant set of images of the most popular politicians' selfies on Twitter ${ }^{4}$. In Table 1 we summarize the main features of our sample.

\begin{tabular}{|l|l|l|c|}
\hline \multicolumn{1}{|c|}{ Politician } & Twitter account & Followers $(\boldsymbol{m l n})$ & Selfie $(\boldsymbol{N})$ \\
\hline Barack Obama & @ BarackObama & 51 & 15 \\
\hline Rania di Giordania & @ QueenRania & 3.38 & 0 \\
\hline Arnold Schwarzenegger & @ Schwarzenegger & 3.13 & 12 \\
\hline David Cameron & @ David_Cameron & 2.8 & 15 \\
\hline Al Gore & @ algore & 2.74 & 6 \\
\hline Shashi Tharoor & @ ShashiTharoor & 2.46 & 13 \\
\hline John McCain & @SenJohnMcCain & 1.92 & 9 \\
\hline Mitt Romney & @MittRomney & 1.59 & 3 \\
\hline Newt Gingrich & @ newtgingrich & 1.49 & 96 \\
\hline Cory Booker & @ CoryBooker & 1.49 & 6 \\
\hline
\end{tabular}

Table 1. Dataset reporting: a) the ten most popular politicians in terms of followers; b) official Twitter accounts of politicians; $c$ ) $N$ of followers per politician; $d$ ) $N$ of selfie per politician (Detection period: 12/01/2013-12/01/2014).

3 http://topsy.com/

$4 \quad$ More specifically, Topsy's browser was set with four research key-words able to provide both tweets belonging to a politician's official Twitter as well as Tweets or ReTweets (RT) containing politicians' Twitter mentions ("@algore") in their body text. Keywords were as follows: a) "\#selfie + Twitter account of politician"; b) “\#selfie +@Twitter account of politician”; c) "selfie + @Twitter account of politician”; d) "selfie + Twitter account of politician". 
Once the sample of images was built, we developed a coding scheme strongly linked to our research questions so that it was immediately interpretive: as suggested by Rose, the codes used must depend on a theorized connection between the image and the broader cultural context in which its meaning is made (Rose 2007). The final version of the codebook, as shown in the Appendix, satisfies the criteria of exhaustiveness and exclusivity of content analysis (Krippendorff 1980). In order to make the application of this set of codes careful and systematic, various tests for inter-coder reliability calculation took place during the research process. The exhaustiveness and exclusivity of the coding categories gave us the chance to quickly encode the selfies by using a binary coding system. ${ }^{5}$ Once recorded, the occurrences of each code in a Google spreadsheet file, we developed absolute frequency counts and selected only those that were particularly significant in the economy of our theoretical as well as empirical framework. Content analysis is a good way to understand the cultural meaning of images (Lutz and Collins 1993). However, since it focuses on the image itself, content analysis is probably not the best way to understand how an image works. For overcoming this limitation, we considered all the hashtags, captions and comments accompanying the politicians' selfies. Taking into account these elements, allowed us to perceive the 'mood' or the 'atmosphere' of a picture that are very hard to catch when the explication exclusively relies on coding categories. Therefore, coherently with this perspective, we attempted to organize the exposure of our findings as shown in the next section.

\section{Findings}

\section{The sense of person beyond the role}

As recently shown by Selfiecity ${ }^{6}$ - the project led by Lev Manovich that used computational and data visualization methods to analyze large amounts of Instagram photos - people actually take less selfies than we think and the majority of selfie takers are in their 20s, with a median age estimated to be 23.7 years. These cultural and demographic parameters confirm why almost all politicians we observed do not extensively use selfies. We discovered that out of a total 171 sampled photos, 149 images were selfies taken by members of the public, who attached these images to self-produced tweets mentioning politicians' twitter accounts in their body-text (e.g. 'I'm honored to take a selfie with the great @David_Cameron' or 'I'm really proud to announce that the person close to me is @algore in person!!'). Only 22 were actually produced by politicians or directly came from their official Twitter profiles.

5 The coding system was substantially based on the assignment of " 0 " or " 1 " value to each node depending on its absence or occurrence within every single coded selfie

6 http://selfiecity.net/ 
Although politicians snap few self-portraits, shooting a selfie with them is a meaningful ritual gesture since it represents the crystallization in image of the contact moment (symbolic as well as substantial) between two traditionally distant realms: politics and society. Thus, in this context, a selfie can be interpreted as a 'Politician-Generated Content' (PGC) in which a politician shows his communication skills by constantly controlling its representation in the public sphere(s) through the adoption of a finely calibrated communication strategy (McNamara 2011). Therefore, in attempting to identify the ways in which politicians promote or reinforce their own public image, we could highlight the presence of some recurring elements that underline and confirm, both the strategic and intentional nature of a politicians' selfie.

Looking at the outcomes of the coding procedure, as a first point we can state that in almost all of the collected selfies $(n=167)$ politicians appear to directly look at the camera. This seems to be mainly related to the need for creating (at least, the illusion of) one-to-one, immediate and transparent relationships with their networked publics. The willingness to establish a close relationship with others is confirmed both by the adoption of an intimate distance from the camera, occurring in nearly a third of the total photos $(n=55)$ and by the positioning of other people - who are almost ever present in the picture, in addition to the politician $(\mathrm{n}=166)$ - with parts of their bodies touching and their heads sloping into each other, suggesting the primacy of relationship.

In accordance with Goffman's theory, all these elements confirm how the politicians of our sample, use selfies as a way to create the sense of a 'person beyond the role' $(1974,298)$. This evidence can be read, at least, in two ways: first, as an attempt by the politician to use his selfportrait with members of civil society in order to build empathetic relationships with a wider online audience made up of followers and supporters; second, as a visual and symbolic answer to the claim to bridge the existing gap between political representatives and civil society (Campus 2010).

\section{Selfie as out-of-frame behaviour}

The sense of a 'person beyond the role' created by selfies has a variable impact on political frames. Instead of enriching their image with elements, attitudes or aspects directly coming from their personal or private life, politicians often uses selfies as a tool to reinforce their primary frame and confirm their profile as servers of public institutions (e.g. 'It was great to hear your inspiring talk today @David_Cameron \& a big thank you for the \#selfie') In this way, the selfie could be better tagged as social media-sustained operation of 'political marketing' (Scammell 1999) with which politicians seem to reaffirm all the social distance deriving from their charismatic role (e.g. The most Happiest Ever lasting moment from you life!! A selfie with @BarackObama!!). This seems to be particularly true for those politicians coming from 
conservative parties such as Mitt Romney, John McCain or Newt Gingrich whose average age (Mean Average Value $=70$-years-old) is much higher than that of the total sample (Mean Average Value $=60$-years-old). In 18 out of 25 selfies, these politicians are portrayed in the context of political or public activities such as attending institutional meetings, giving an electoral speech or enjoying a political rally. These self-representations appear as instrumental to the reinforcement of a widely stable image of the good, wise and busy politician (Fig. 1).

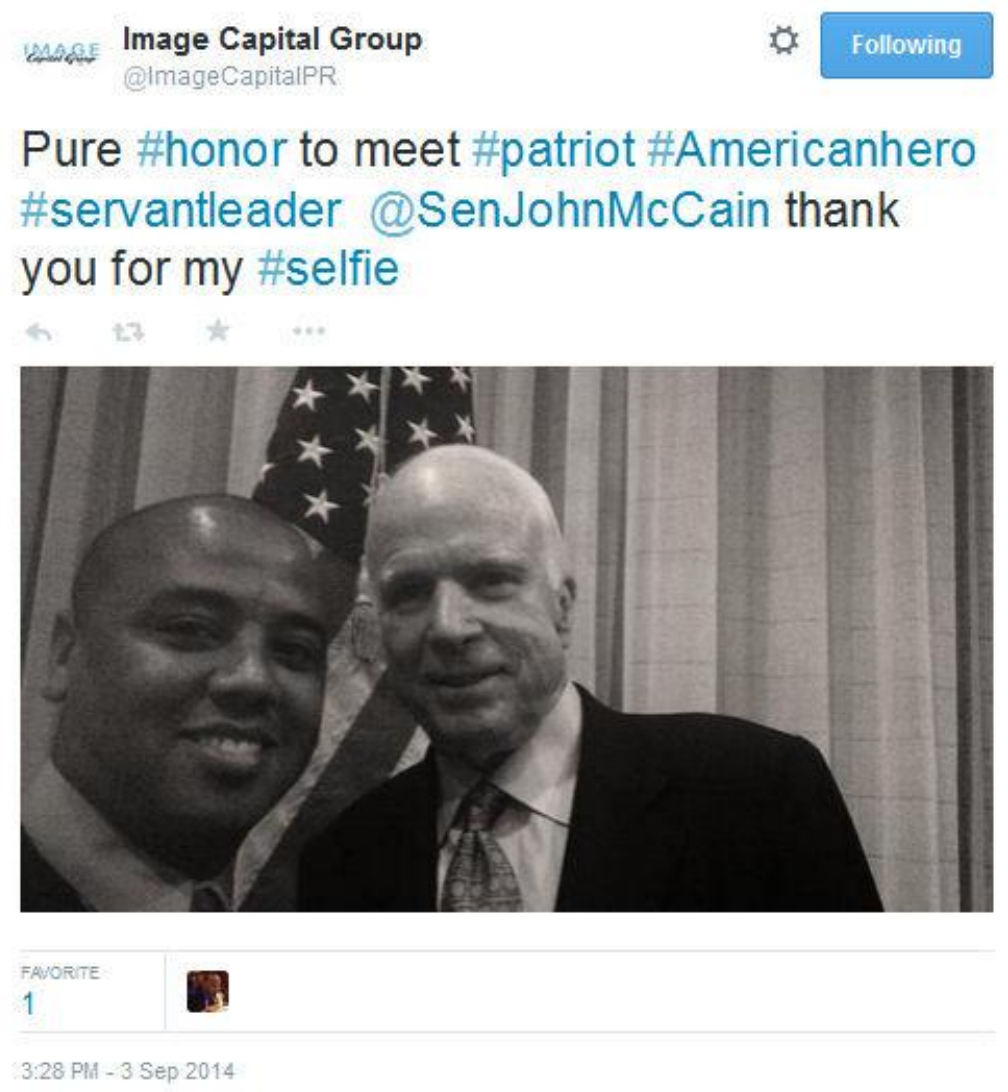

Figure 1.

Coherently with this kind of political identity building, family members (especially children or wives) are frequently involved in order to remark some moral or ethical qualities of the 'charismatic' leader instead of really shedding light on the personal sphere (Fig. 2). 


\section{Plane \#selfie with@CallyGingrich and @TimPawlenty on our flight to Minneapolis this afternoon!}

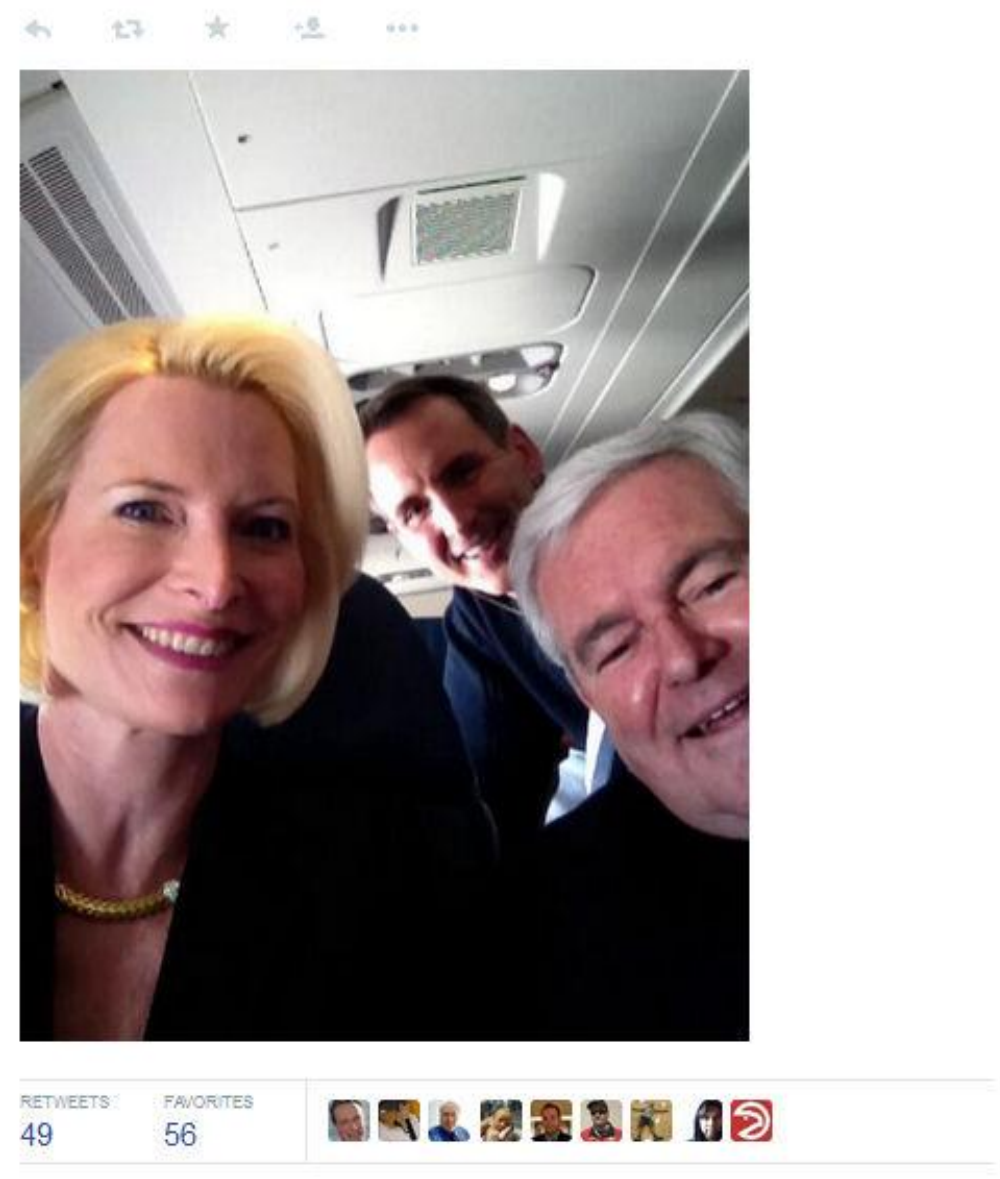

11:29 AM - 14 Mar 2014

Figure 2.

At the opposite pole of the political spectrum, we found that two of the main representatives of US democrats, Al Gore and Obama, use selfies to strengthen the relationship between their public image and the political interest for public affairs (e.g. 'Day early \#TBT: @algore \#selfie July 12, 2005. Great seeing him again last night: @ civilbeat'). This is confirmed, in particular, by the selfies in our sample that are taken with members of the public attending conferences, TV programs and institutional appointments centered on civic or social issues (e.g. '@BarackObama recognizes @ConwayRegional's ER Dept. We r proud of their work'). In all these cases, the selfie constitutes an out-of-frame behaviour that occurs during the performance of a particular 
role. When politicians take a selfie during activities directly tied to their political identity, they are showing the limits placed upon the claims of their role (Goffman 1974, 273). Hence, snapping a selfie is an out-of-frame behavior, that many politicians of our sample use to reinforce their primary political frame $(\mathrm{n}=70)$.

\section{Selfie as out-of-role behaviour}

Other politicians such as Cory Booker and Arnold Schwarzenegger share many selfies within frame that are not directly tied to political contexts. In this case, the act of self-portraits defines an out-of-role behaviour Cory Booker - the youngest democratic politician of our sample (45years-old) and the most engaged on Twitter (e. g. '@CoryBooker is on a mission to take a \#selfie with every US senator'; 'Ha! RT @ girlsgottaeatdc: Obligatory Cory Booker \#selfie') - takes selfies during activities such as running, eating or preparing vegan dishes (Fig. 3).

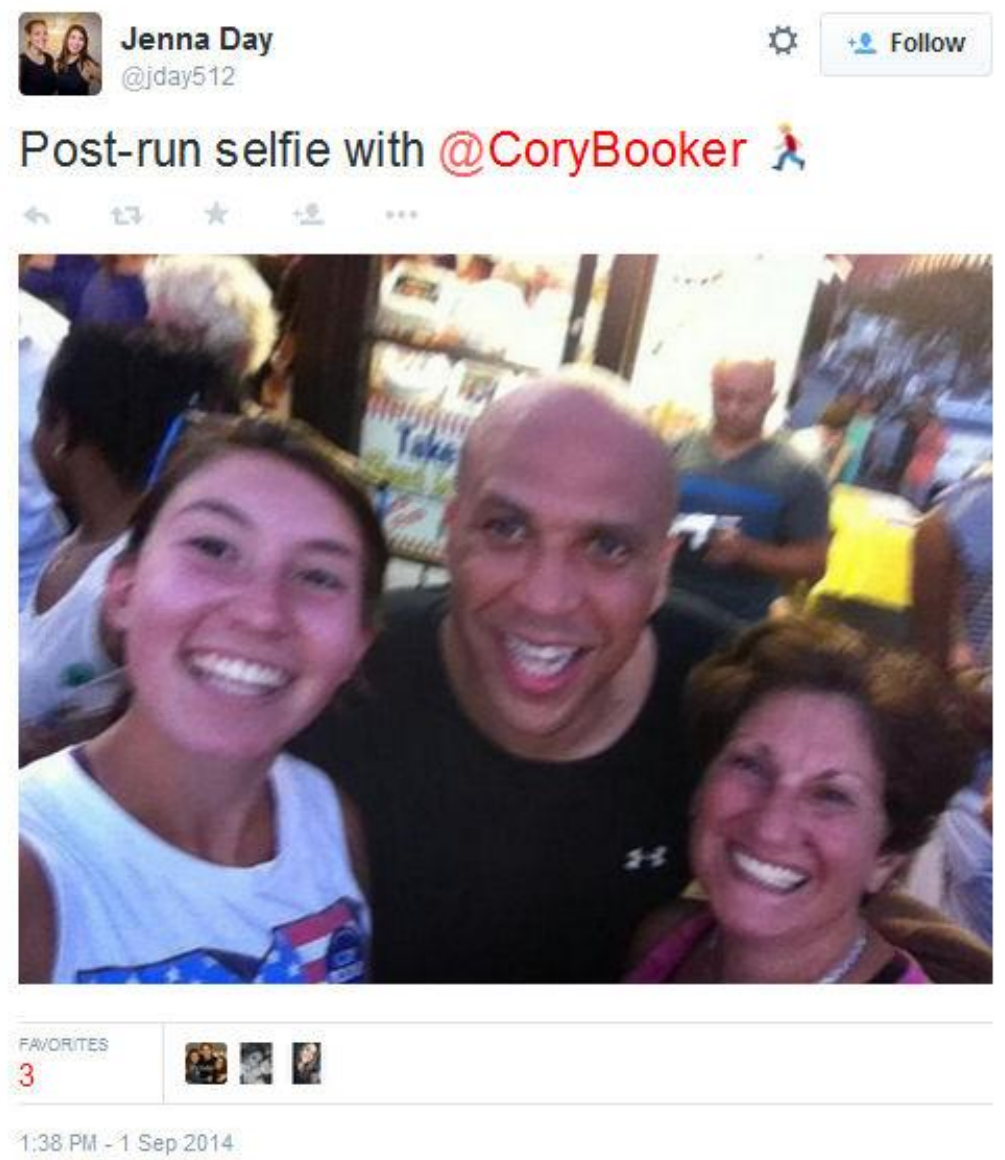

Figure 3. 
Booker's goal is to build 'peer-to-peer' relationships with potential voters -Twitter users - both by controlling the exposure of aspects belonging to his private life and using the selfie just as the public do (e.g. 'Great meeting @ corybooker last night. This is a man who knows how to take a selfie!'). At the same time, Arnold Schwarzenegger, coming from a Hollywood star system culture, often uses selfies in order to self-promote himself as politician by constantly overlapping his image as movie star and that of successful Republican politician (Fig. 4).

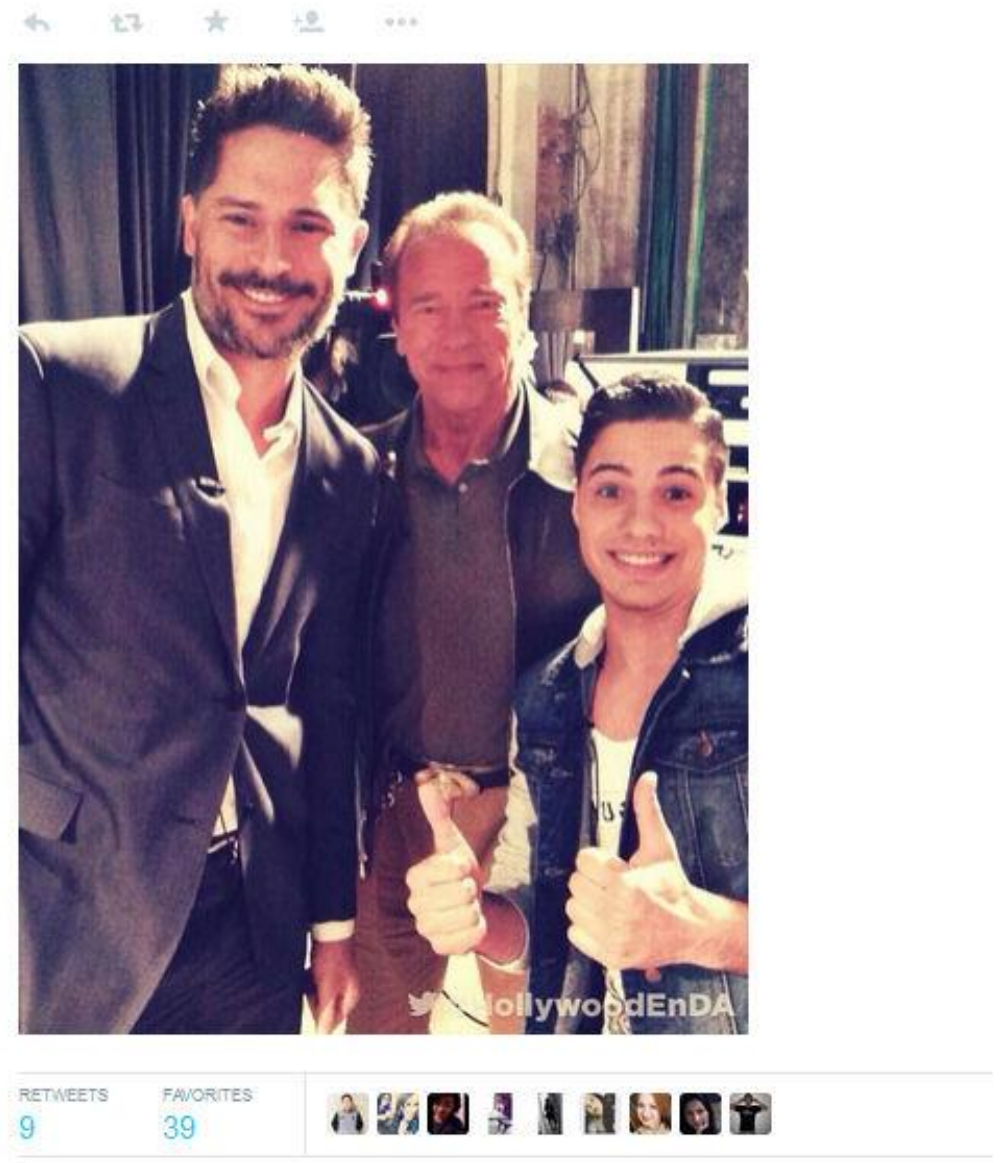

Figure 4. 
As suggested by Goffman's theory, when an individual is engaged in activity that is quite unsuitable for him, that activity cannot easily be seen as compatible with what he brings to his role and takes away from them, he may playfully transform what he does into playfulness, so that the whole scene is conducted out of role $(1974,274)$. When politicians take selfies during activities that are not directly tied to their political identity, as in the case of Cory Booker and Arnold Schwarzenegger, they are showing how their role is not independent of the apparently irrelevant features of those engaged in projecting it. Making a selfie is an out-of-role behaviour that many politicians of our sample use to enlarge their primary political frame $(n=99)$.

\section{Selfie as breaking frame}

As mentioned above, most politicians' selfies we found were taken and shared by members of the public. As a product of a generalized fifth moment of photography - that of complete mobility, ubiquity and connection of images in the same single device (Gómez Cruz and Meyer 2013) - selfies are made to be shared on social media (Tifentale and Manovich 2014). For users, taking a selfie with a politician and sharing it within a semi-public space as Twitter is ance a private act as well as a public activity, a tool to manage their online self-representation and a way to express affiliation to a certain community of cultural and political values in a highly ritualized way (Mendelson and Papacharissi 2011). Politicians' selfies, to a certain extent, constitute examples of civic narcissism (Papacharissi 2010): released from its pathological sense, narcissism in a social network is the ability to use political thoughts not with the explicit intention of increasing civic engagement, but as a mode to express yourself. In our case, most politicians' selfies circulating on Twitter are largely self-referential and motivated by personal fulfillment (e.g. 'I just took a selfie with @CoryBooker and I am ridiculously happy'). On the one hand, users share political images they favor and try to integrate them in their social experience; on the other hand, users actively participate in content production by using inspiration from the more famous politicians' selfies and try to compete with them, as in the 'beat this selfie' game (e.g. 'Epic \#Selfie w/ Comm Pryor, Adam, and I on my final day on staff yesterday. Beat this Selfie @CoryBooker ha \#edchat'; 'What selfie is better? @dj_tigerlily @BarackObama lol' ).

In other cases, the act of taking a selfie is closely combined with its consumption, reuse and repetition. The photoshopping of politicians' images, for instance - the post-production manipulation of an image with ad hoc PC software - shows how people use a politicians' selfie as a way of living their fantasies and dreams, which can never be achieved in real life, as in the fake self-portraits with Obama (Fig. 5). 


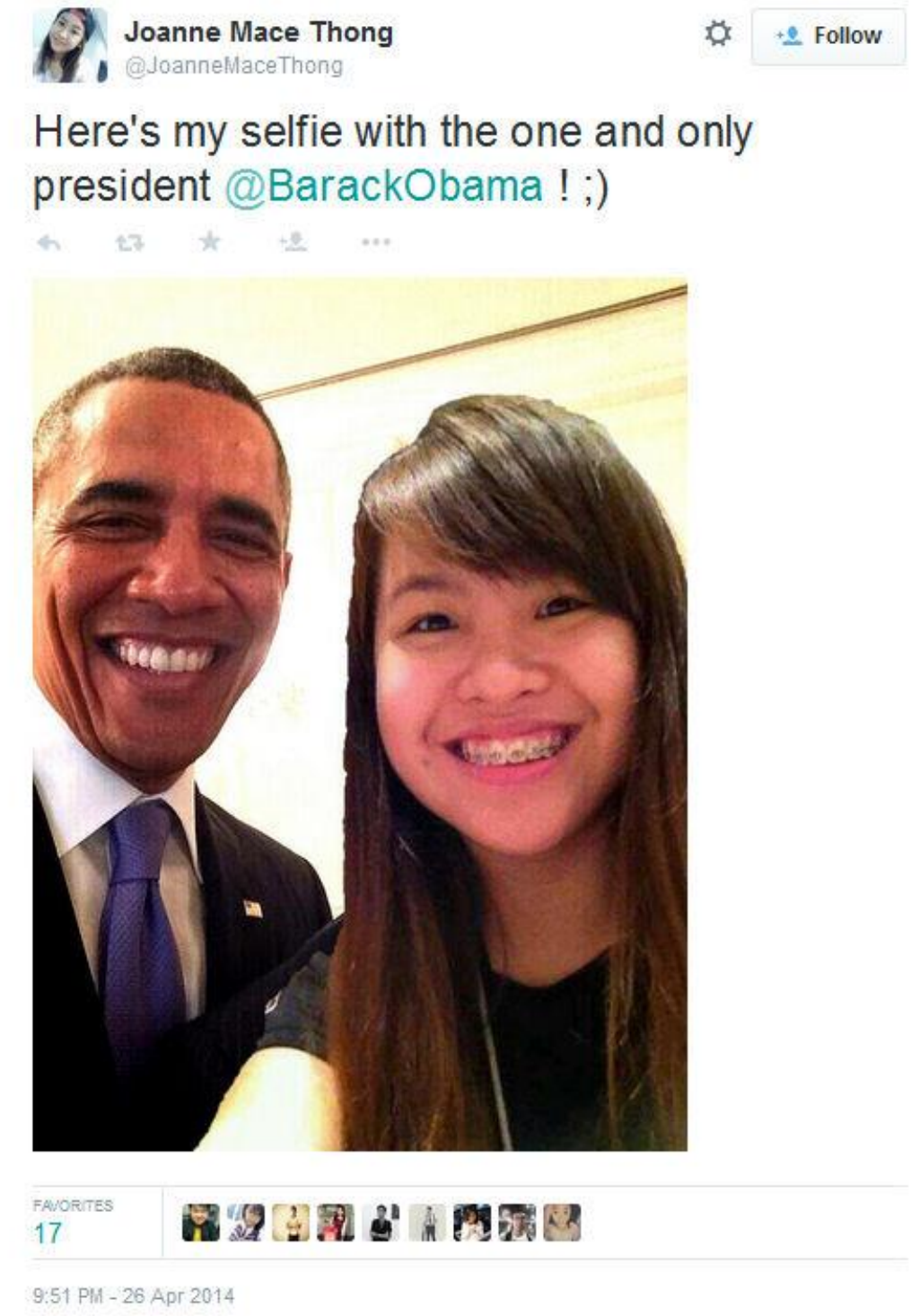

Figure 5.

Other photoshopping images are typical examples of fan-related textual poaching (Jenkins 1992): users take the most shared images on Twitter and utilize them to create a new photographic composition, usually with the aim of mocking famous politician's selfies. Another way to make an ironic use of the selfie is the reverse photobombing with politicians. In this case, the apparent subject of the image, conventionally the bombee, takes a selfie to capture an unaware politician within the frame of the image, making him the unintentional bomber of the picture. As shown in our sample, this practice mainly involves the most prominent politicians: 
throughout one year of Twitter activity, 29 selfies out of 46 were detected as examples of reverse photobombing with the hashtag ‘@BarackObama' (Fig. 6).

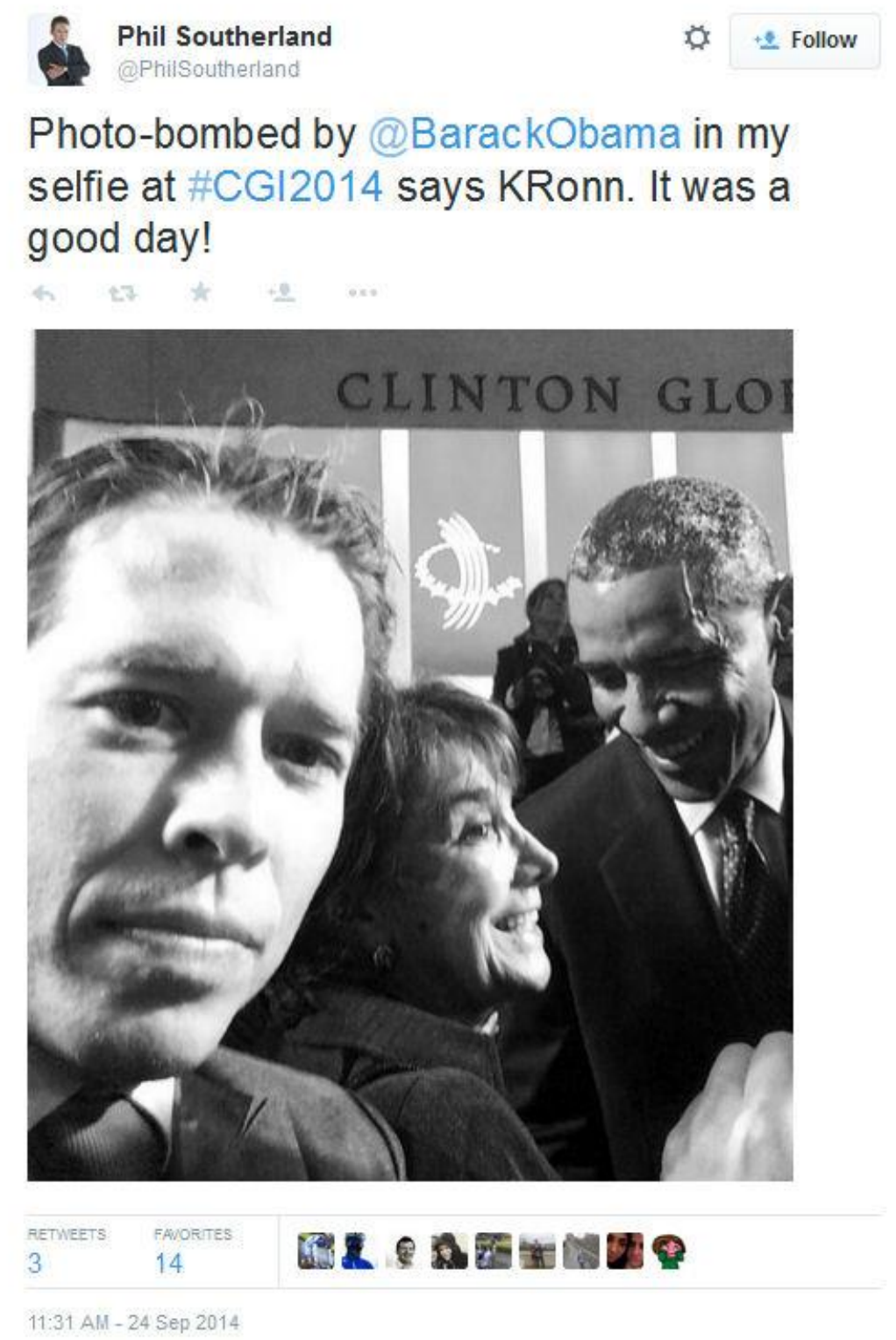

Figure 6.

Using Goffman's theory, we are faced with cases of breaking frame (1974, 345). When an individual takes part in the definition of a situation - as in the case of politicians and his primary political frame - circumstances can cause him suddenly to let go of the grasp the frame has upon him. In our examples, this disengagement is caused by users in the form of upkeying, an unauthorized increase in lamination of the frame $(1974,366)$. The 'beat this selfie' game, fake 
self-portraits or reverse photobombing are all examples of upkeying, in which the special realm of the game takes the place of the daily activities. These upkeyings make the selfie a decontextualized digital artefact that allows us to reflect - usually with ironic determinations on the meaning of celebrity within contemporary mainstream culture.

\section{Conclusions}

There is nothing new about the need faced by politicians to construct their self-images and to control their self-presentation: the management of public visibility is an ancient political art (Thompson 1995). But, if with the development of mass media communication - from the early form of print to mainstream television - political rulers had to concern themselves with their self-presentation before audiences which were not physically present, nowadays the current visual turn in social media provides a new kind of visibility that is changing the rules by which this art is practised. This new kind of visibility requires that politicians display a more casual and colloquial image, creating a closer, unmediated relationship with their audience (Săvulescu \& Viţelar 2012). The selfie would be a good way to satisfy this need. Selfies are snapshots whose aesthetics and cultural function are closely aligned with 'authenticity', leading us to believe that they are conveying some fundamental 'truth' about their authorial subject (Coladonato 2014). As shown in our findings, all politicians exploit some distinguishing features of the selfie - direct look, intimate distance from camera lens and from other people in the picture - as a genuine expression of spontaneity. Politicians' selfies represent the crystallization in image of a 'parasocial relationship' (Horton and Wohl 1959), the traditional one-sided relationship that can occur in television when an actor faces the spectator, uses the mode of direct address, in talking as if he were conversing personally and privately, giving the illusion of face-to-face interaction. In this kind of broadcast performance, political figures can strategically provide themselves with personal identity beyond their public role, presenting a proof of authenticity to their audience and giving an illusion of intimacy. This sense of person beyond the role created by selfies has variable impact on political frame. As shown in our findings, some politicians use the selfie as an out-of-frame behaviour that serves to reinforce their political frame, whereas others use self-portraits as an out-of-role behaviour that serves to enlarge their primary political frame. In both cases, politicians mark the limit to which their current role can hold them - an open admission that they have a continuing biography, a single personal identity beyond every framed activity. As claimed by Goffman, this personal biography ensures a continuity of absolute distinguishableness, that is, selfsameness $(1974,287)$.

But such practices are not totally new: television has blurred the line between front and back regions in politics, creating a new 'middle region' that emphasizes political personality over role (van Aelst et al. 2010). But, whereas in television, the continuous presence of politicians as 
'ordinary' people may lead to an over-exposure that diminishes their credibility (Meyrowitz 1985), this risk is less obvious in social media because the attention on 'personal life' and 'personal characteristics' of political leaders is delegated to users. As we show, most people turn politicians' selfies into decontextualized digital artefacts that break the primary political frame. Nevertheless, all these practices of user-generated content end up making the politician appear more accessible and human, reinforcing the cultural significance of his celebrity rather than disapproving it and confirming an aura of authenticity, albeit in its most surreal form (Fletcher \& Greenhill 2010). Thanks to the selfie, politicians can fulfill their quest for celebrification without having to rely on traditional strategies of visibility and spectacularization characterizing mass media communication (Baroncelli and Freitas 2011).

The selfie is not just a means of saying, 'look at me' within the public space. Rather, politicians make their public identity statements in an implicit way, concealing any intentional act of selfrepresentation within the same frame of images and texts published online by various users, tagged as selfies and entrusted to third parties that manage and redistribute these contents. Taking advantage of the formulaic nature of selfies and their tendency to repetition and reuse, politicians can enact all these performative gestures (Papacharissi 2012) - social cohesion, uniqueness, spontaneity, irony, micro-celebrity - that serve to enhance their need for authenticity in an indirect manner, leaving users the task of making and sharing their self-portraits on Twitter. Rather than representing an extension of the spectacle into everyday life or a strategy of selfbranding, politicians use the selfie as a space of appearance (Iqani 2013), in which they can declare to others 'Hey! Watch me while I do one of those self-photo things that all the kids are doing'. In this way, they facilitate new forms of parasocial identification, which allows audience to 'read' their political characters and 'taste' their style, enabling them to judge their claims of authenticity and competence in a more effective manner (Corner and Pels 2003).

\section{Appendix 1 (Codebook)}

\begin{tabular}{|l|l|}
\hline Node & Description \\
\hline Direct look & Politician's look is towards camera \\
\hline Non-direct look & Politician do not directly look into the photographic lens. \\
\hline Formal clothing & $\begin{array}{l}\text { Use of specific dressing code which is recognized to be 'formal' within } \\
\text { specific political or cultural contexts (as in the case of jacket, tie or shirt } \\
\text { for many Western politicians). }\end{array}$ \\
\hline Informal clothing & $\begin{array}{l}\text { Adoption of clothes that are considered to be not properly 'usual' for } \\
\text { political personae (e.g t-shirts or shorts). }\end{array}$ \\
\hline Politician's facial expression & $\begin{array}{l}\text { Expression of sentiments through the adoption of socially recognized face } \\
\text { attitudes (happy, serious or angry) }\end{array}$ \\
\hline
\end{tabular}




\section{November 2015}

\begin{tabular}{|c|c|}
\hline Politician as unique subject of selfie & Politician is the only subject of selfie. \\
\hline Politician as not unique subject of selfie & Politician is portrayed with other people. \\
\hline Others as VIP & $\begin{array}{l}\text { Individuals hailing from the star system such as famous actors, singers or } \\
\text { sports players. }\end{array}$ \\
\hline Others as politicians/institutions & Political personalities or public institutions representatives \\
\hline Others as family members & Relatives, children or wives \\
\hline Others as common people & $\begin{array}{l}\text { Unknown people such as political supporters, fans or common people } \\
\text { attending public events or election rallies. }\end{array}$ \\
\hline Distance from camera lens - intimate & $\begin{array}{l}\text { Distance is defined as 'intimate' when it is possible to see only some parts } \\
\text { of the body of politicians, such as the face and eyes or the subject is so } \\
\text { close to the camera lens that a part of his head is cut off (close up) }\end{array}$ \\
\hline Distance from camera lens - personal & $\begin{array}{l}\text { Distance is defined as 'personal' when it is possible to see more sections } \\
\text { of the politicians' body as chest and arms (half-length photo) }\end{array}$ \\
\hline Distance from camera lens - social & $\begin{array}{l}\text { Distance is defined as 'social' when all the politicians' body and other } \\
\text { people can be seen(full length) }\end{array}$ \\
\hline Distance from other(s) (if present) - intimate & $\begin{array}{l}\text { Distance from others is called 'intimate' when the two people (or more) in } \\
\text { the picture touch or hug each other }\end{array}$ \\
\hline Distance from other(s) - personal & $\begin{array}{l}\text { Distance from others is called 'personal' when the two people (or more) in } \\
\text { the picture are separated by less than an arms' length. }\end{array}$ \\
\hline Distance from other(s) - social & $\begin{array}{l}\text { Distance from others is called 'social' when two people (or more) in the } \\
\text { picture are separated by an arms' length or more. }\end{array}$ \\
\hline $\begin{array}{l}\text { Impact on primary/political frame- } \\
\text { enlargement }\end{array}$ & $\begin{array}{l}\text { 'Enlargement' of primary/political frame happens when the representation } \\
\text { of a politician is related to leisure contexts (opening of commercial } \\
\text { activities, cultural events, sport events) or with specific people (supporters, } \\
\text { friends) that are functional to his/her political image redefinition as well as } \\
\text { construction. }\end{array}$ \\
\hline $\begin{array}{l}\text { Impact on primary/political primary frame- } \\
\text { break }\end{array}$ & $\begin{array}{l}\text { 'Break' of primary/political frame happens when the representation of } \\
\text { politicians through selfies is related to private contexts (events, life } \\
\text { moments, and family people) that are not linked to politics or political } \\
\text { affairs. }\end{array}$ \\
\hline $\begin{array}{l}\text { Impact on primary/political frame- } \\
\text { reinforcement }\end{array}$ & $\begin{array}{l}\text { 'Reinforcement' of primary frame happens when the representation of } \\
\text { politician through selfie is related to contexts (speaks at conferences or } \\
\text { election rallies, open schools or deliver a speech in front of his/her own } \\
\text { parliament, attend TV interviews or press conferences) or people (other } \\
\text { politicians) that are directly tied to his/her political identity. }\end{array}$ \\
\hline ReTweet $(N)$ & $\begin{array}{l}\text { Twitter function allowing people sharing contents produced by others. For } \\
\text { our purposes, this metric has been used in order to highlight how many } \\
\text { times tweets containing politicians' selfies have been shared by other } \\
\text { people. }\end{array}$ \\
\hline Favourites $(N)$ & $\begin{array}{l}\text { This Twitter function regards the chance for people to tag a tweet as } \\
\text { 'favourite'. Here this metric was interpreted only in a quantitative way or, } \\
\text { more precisely, in order to understand the propagation level of each selfie. }\end{array}$ \\
\hline
\end{tabular}

Table 2. Description of nodes used for analyzing politicians' selfies (Detection period: 12/01/2013-12/01/2014) 


\section{References}

Adam, S. and Maier, M. (2010) 'Personalization of Politics: A Critical Review and Agenda for Research', in C. T. Salmon (ed), Communication Year Book 34, New York: Routledge, pp. 213-257.

Baroncelli, L. and Freitas, A. (2011) 'The Visibility of the Self on the Web: A Struggle for Recognition', Proceedings of the ACM WebSci'11, June 14-17 2011, Koblenz, Germany, pp. 1-2. Available at http://journal.webscience.org/502/. Accessed 20 December 2014.

Baum, M. (2005) 'Talking the Vote: Why Presidential Candidates Hit the Talk Show Circuit', American Journal of Political Science, 49 (2), pp. 213-234.

Benoit, K. and Laver, W. (2006) Party Policy in Modern Democracies, London: Routledge.

Berger, J. (1972) Ways of Seeing, London: British Broadcasting Corporation and Penguin Books Ltd.

Berger, L. (2011) ‘Snapshots, or: Visual Culture's Clichés’, Photographies, 4(2), 175-190.

Boccia Artieri, G. (2012) Stati di connessione. Pubblici, cittadini e consumatori nella (Social) Network Society, Franco Angeli, Milano.

boyd, d. (2014) It's Complicated: The Social Lives of Networked Teens, New Haven, CT: Yale University Press.

Bruno, N., Gabriele, V., Tasso, T. and Bertamini, M. (2013) 'Selfies' Reveal Systematic Deviations from Known Principles of Photographic Composition', Art \& Perception, 2, 45-58.

Campus, D. (2002) 'Leaders, Dreams and Journeys: Italy's New Political Communication', Journal of Modern Italian Studies, 7 (2), 171-191.

Campus, D. (2010) 'The Mediatization and Personalization of Politics in Italy and France: The Cases of Berlusconi and Sarkozy’, International Journal of Press Politics, 15 (2), 219235.

Cartwright, L. and Sturken, M. (2001) Practices of Looking. An Introduction to Visual Culture, Oxford: Oxford University Press. 
Chalfen, R. M. (1987) Snapshot Versions of Life, Bowling Green Ohio: Bowling Green State University Popular Press.

Chandler, L. and Livingston, D. (2010) 'Reframing the Authentic: photography, mobile technologies and the visual language of digital imperfection', Available at http://www.inter-disciplinary.net/at-the-interface/wpcontent/uploads/2012/05/chandlervlpaper.pdf. Accessed on December 20th, 2014.

Coladonato, V. (2014) 'Power, Gender, and the Selfie. The cases of Hillary Clinton, Barack Obama, Pope Francis', in A. Cati, M. Fanchi, and R. Maule, (eds), Comunicazioni sociali n.3, Milano: Vita e Pensiero, 394-405.

Corner, J., and Pels, D. (eds) (2003). Media and the restyling of politics: Consumerism, celebrity and cynicism, London: Sage.

Cruz, E.G. and Meyer, E.T. (2012) 'Creation and Control in the Photographic Process: iPhones and the emerging fifth moment of photography', Photographies 5(2).

Dakhlia, J. (2010) 'Une chute du 'mur français de la vie privée? La peopolisation politique des années 2000', The Web Journal of French Media Studies, 8. Available at http://wjfms.ncl.ac.uk/. Accessed on December 20th, 2014.

Dalton, R. J. and Wattenberg, M. P. (2000) Parties Without Partisans: Political Change in Advanced Industrial Democracies, Oxford: Oxford University Press.

Dobson, A.S. (2014) 'Performative shamelessness on young women's social network sites: Shielding the self and resisting gender melancholia', Feminism \& Psychology 24, 97-114.

Fausing, B. (2013) 'Selfie and The Search for Recognition: See for your Selfie'. URL: https://www.academia.edu/4418191/Selfies_and_the_Search_for_Recognition._See_for_ your_Selfie. Accessed on December 20th, 2014.

Fletcher, G. and Greenhill, A. (2010) 'Photobombing: Mobility, Humour and Culture', Proceedings Cultural Attitudes Towards Communication and Technology, 2010, Murdoch University, Australia, 198-206.

Goffman, E. (1974) Frame Analysis. An Essay on the Organization of Experience, Boston: Northeastern University Press. 
Hall, E. T. (1963) 'A System for the Notation of Proxemic Behavior', American Anthropologist 65 (5): 1003-1026.

Hand, M. (2012) Ubiquitous Photography, Cambridge: Polity Press.

Helms, L. (2005) 'The Presidentialisation of Political Leadership: British Notions and German Observations', The Political Quarterly, 76 (3), 430-438.

Hogan, B. (2010) 'The presentation of self in the age of social media: Distinguishing performances and exhibitions online', Bulletin of Science Technology \& Society, 30 (6), 377-386.

Horton, D. and Wohl, R. (1956) 'Mass Communication and Parasocial Interaction: Observations on Intimacy at a Distance', Psychiatry, 19: 215-29.

Iqani, M. (2013) 'Spectacles or Publics? Billboards, magazine covers, and 'selfies' as spaces of appearance', Wits Interdisciplinary Seminar in the Humanities (WISH) Seminar WISER, 11 November 2013. Available at http://wiser.wits.ac.za/content/spectacles-or-publicsbillboards-magazine-covers-and-\%E2\%80\%98selfies\%E2\%80\%99-spaces-appearance10959. Accessed on December 20th, 2014.

Jenkins, H. (1992) Textual Poachers: Television Fans and Participatory Culture, New York: Routledge.

Jenkins, H. (2010) 'Transmedia storytelling and entertainment: An annotated syllabus', Continuum: Journal of Media \& Cultural Studies, 24 (6), 943-958.

Jenkins, H. (2013) Spreadable Media: Creating Value and Meaning in a Networked Culture, New York: New York University Press.

Karvonen, E. (2009) 'Entertainmentization of the European Public Sphere and Politics, in J. Harrison and B. Wessels (eds), Mediating Europe: New Media, Mass Communications and the European Public Sphere, Oxford: Berghahn Books, pp. 99-127.

Krippendorff, K. (1980) Content Analysis; An Introduction to its Methodology, Beverly Hills, CA: Sage. 
Larsson, A. O. (2014) 'Online, all the time? A Quantitative Assessment of the Permanent Campaign on Facebook', New Media \& Society.

Lasén, A. and Gómez-Cruz, E. (2009) 'Digital Photography and Picture Sharing: Redefining the Public/Private Divide. Knowledge', Technology \& Policy, 22, 205-215.

Lüders, M., Prøitz, L. and Rasmussen, T. (2010) 'Emerging personal media genres'. New Media Society 12, 947-963.

Lutz, C. A. and Collins, J. L. (1993) Reading National Geographic, Chicago: University of Chicago Press.

MacNamara, K. (2011) 'The Paparazzi Industry and New Media: The Evolving Production and Consumption of Celebrity News and Gossip Websites', International Journal of Cultural Studies, 14 (5), 516-630.

Manin, B. (2010) 'Principi del Governo Rappresentativo’, Icon, 39 (051).

Marsh, D., Hart, P. and Tindall, K. (2010) 'Celebrity politics: The politics of the late modernity?', Political studies review, 8(3), 322-340.

Marwick, A. E. and boyd, d. (2010) 'I tweet honestly, I tweet passionately: Twitter users, context collapse, and the imagined audience', New Media \& Society 13 (1), 114-133.

McAllister, I. (2007) 'The Personalization of Politics', in R. J. Dalton and H. D. Klingemann (eds) Oxford Handbook of Political Behavior, New York: Oxford University Press, pp. 571-588.

Mendelson, A. L. and Papacharissi Z. (2011) 'Look at us: Collective Narcissism in College Student Facebook Photo Galleries', in Papacharissi, Z. (ed.), A Networked Self: Identity, Community and Culture on Social Network Sites, New York and London: Routledge, pp. 251-273.

Meyrowitz, J. (1985) No Sense of Place: The Impact of Electronic Media on Social Behaviour, New York: Oxford University Press.

Mulvey, L. (1975) 'Visual Pleasure and Narrative Cinema', Screen 16(3): 6-18.

Murray, S. (2008) 'Digital Images, Photo-Sharing, and Our Shifting Notions of Everyday Aesthetics', Journal of Visual Culture, (7): 147. 
Papacharissi, Z. (2010) 'The Virtual Sphere 2.0: The Internet, the Public Sphere and beyond', in A. Chadwick and P.N. Howard (eds), The Routledge Handbook of Internet Politics, Abingdon: Routledge, pp. 230-245.

Papacharissi, Z. (2012) 'Without You, I'm Nothing. Performances of the Self on Twitter', International Journal of Communication 6 (2012), 1989-2006.

Piela, A., 2013. 'I am Just Doing my Bit to Promote Modesty: Niqabis' self-portraits on photosharing websites', Feminist Media Studies 13, 781-790.

Rose, G. (2007) Visual Methodologies, London: Sage.

Scammell, M. (1999) 'Political Marketing: Lessons for Political Science', Political studies, 47 (4), 718-739.

Schroeder, J. E. (2012) 'Style and Strategy: Snapshot Aesthetics in Brand Culture', in Puyou, F.R, Quattrone, P., McLean, C. and Thrift, N. (eds), Imagining organizations: performative imagery in business and beyond, London: Routledge.

Schwarz, O. (2010). 'On Friendship, Boobs and the Logic of the Catalogue Online Self-Portraits as a Means for the Exchange of Capital', Convergence 16, 163-183.

Săvulescu, R. and Viţelar, A. (2012) 'Pics or It Didn’t Happen: Analyzing Facebook Photographs of Romanian Women Politicians', Romanian Journal of Communication and Public Relations, 1(2012), 7-20.

Seko, Y., (2013) 'Picturesque Wounds: A Multimodal Analysis of Self-Injury Photographs on Flickr', Forum: Qualitative Social Research, Vol. 14, No 2 (2013), 1-23.

Stanyer, J. (2008) 'Elected Representatives, Online Self-Presentation and the Personal Vote: Party, Personality and Webstyles in the United States and United Kingdom', Information, Communication and Society, 11 (3), 414-431.

Stanyer, J. (2013) Intimate Politics, Cambridge: Cambridge Polity Press.

Thompson, J. B. (1995) The Media and Modernity. A Social Theory of the Media, Cambridge: Polity Press. 
Tifentale, A. and Manovich, L. (2014) 'Selfiecity: Exploring Photography and Self-Fashioning in Social Media'. Available at http://manovich.net/index.php/projects/selfiecity-exploring. Accessed on December 20th, 2014.

van Aelst, P., Sheafer, T. and Stanyer, J. (2011) 'The personalization of mediated political communication: A review of concepts, operationalizations and key findings', Journalism 13(2), 203-20.

van Zoonen, L. (2005) Entertaining the Citizen: When Politics and Popular Culture Converge, Lanham, MD: Rowman and Littlefield.

Vivienne, S. and Burgess, J. (2013) 'The remediation of the personal photograph and the politics of self-representation in digital storytelling', Journal of Material Culture, 18(3), 279298.

Walker Rettberg J. (2014) Seeing Ourselves through Technology. How We Use Selfies, Blogs and Wearable Devices to See and Shape Ourselves, Palgrave Macmillan.

West, D. M. and Orman, J. (eds) (2003) Celebrity Politics, Upper Saddle River, NJ: Prentice Hall.

Manolo Farci, Post Doc Research Fellow at the Department of Communication Sciences and Humanistic Disciplines at the University of Urbino Carlo Bo (Italy) and member of Center LaRica (Research Laboratory in Advanced Communication). His main research interests revolve around media and visual studies and the impact of technology on notions of identity. Among his recent publications: Lo sguardo tecnologico. Il postumano e la cultura dei consumi (Milan 2012).

Email: Manolo.farci@uniurb.it

Mario Orefice, Post Doc Research Fellow at the Department of Communication Sciences and Humanistic Disciplines at the University of Urbino Carlo Bo (Italy) and member of Center LaRica (Research Laboratory in Advanced Communication). His research areas regard political participation and social movements. On these topics he realized, since 2013, his PhD dissertation as well as some other works published in national and international journals.

Email: Mario.orefice@uniurb.it 